\title{
Validation of intercultural sensitivity three- factor model in Malaysian context
}

\author{
Norzita Yunus ${ }^{1,2, *}$, Ezhar Tamam ${ }^{2}$, Jusang Bolong ${ }^{2}$, Nor Azura Adzharuddin ${ }^{2}$, and Faridah \\ Ibrahim $^{1}$ \\ ${ }^{1}$ Infrastructure University Kuala Lumpur, Jln. Ikram-Uniten, 43000 Kajang, Selangor, Malaysia \\ ${ }^{2}$ Universiti Putra Malaysia, 43400 Serdang, Selangor, Malaysia
}

\begin{abstract}
A plethora of studies have indicated the importance of intercultural sensitivity (IS) in today's highly interconnected, global world. Despite that, in Malaysian context, very limited reliable instruments are available to measure intercultural sensitivity. A study using Malaysian dataset by Tamam (2010) found a three-factor model of the Chen and Starosta's five-factor model of Intercultural Sensitivity Scale (ISS); however, the model was exploratory and has yet to be validated. Therefore, the purpose of this study was to further validate the intercultural sensitivity three-factor model within Malaysian collectivistic and multicultural context. Using survey as a means of data collection, 1000 undergraduate students at three higher education institutions completed self-administered questionnaires. The three-factor model found earlier was subject to Confirmatory Factor Analysis using Analysis of Moments Structures (Amos) software. The results showed that the intercultural sensitivity three-factor model showed a good fit thus indicating that the three-factor model is a viable alternative to the original model. In conclusion, the threefactor model is a valid and reliable instrument to measure intercultural sensitivity within Malaysian collectivistic and multicultural context.
\end{abstract}

\section{Background of study}

Within today's globalised and highly interconnected world, the ability to communicate across cultures is no longer an option. Numerous studies have established the importance of intercultural sensitivity (IS) as an important requisite for communication across cultures e.g. [1-11]. Cultural diversity is apparent in almost every sector. Within workplace contexts, according to Llyod and Hartel [12], organisations are recruiting employees from diverse backgrounds in optimising organisational outcomes. Within the higher education industry, cultural diversity is apparent in the increasing number of students involved in cross-border education (CBE).

*Corresponding author: norzita@iukl.edu.my 
According to the United Nations Educational, Scientific and Cultural Organisation [13], the number of students studying abroad has shown a tremendous growth. With less than 200,000 students studying abroad in 1950 s, the number is projected to grow to more than seven million by the year 2020. Within Malaysian multicultural and multi-religious context, intercultural sensitivity is inarguably crucial thus creating the need for more studies on the role of IS within Malaysian context. In undertaking these studies, a valid and reliable instrument to measure intercultural sensitivity is required. However, there is very limited reliable instrument available to measure intercultural sensitivity within Malaysian context. One of the very few instruments available is Tamam's [14] intercultural sensitivity threefactor model which is a local version of the Chen and Starosta's five-factor Intercultural Sensitivity Scale (ISS).

Nonetheless, the three-factor model requires further validation due to the limitations of the study. First, the model is exploratory thus is subject to further validation. Second, the model was produced from a single site study thus limiting its generalisability. Next, the study measured intercultural sensitivity based on intra-national interactions, which refers to interactions that occur among the multi-ethnic Malaysian undergraduate students. According to Kamal and Maruyama [15], intra-national interactions may not be as complex as cross-national interactions as the members share to a certain extent the same meaning of common symbols such as language and some cultural practices. Cross-national interaction refers to interactions that occur among local and international students who are of different nationality. In today's globalised world, Malaysians are not only limited to intra-national interactions thus measuring intercultural sensitivity from a cross-national perspective would be highly beneficial. Further, ISS requires replication and psychometric testing particularly in a non-American context $[16,17]$.

Therefore, the purpose of the present study is to extend previous work on IS by validating the three-factor model within Malaysian collectivistic context. This is done by addressing the limitations mentioned earlier. First, the three-factor model which was produced based on exploratory factor analysis (EFA) was subject to Confirmatory Factor Analysis (CFA). Second, data collection was carried out at multiple sites thus extending the generalisability of the findings. Third, the sample was undergraduate students who engaged in cross-national interactions; which means that intercultural sensitivity was measured based on respondents' engagement in interactions with international students on campus.

\section{Intercultural Sensitivity Scale}

Intercultural sensitivity (IS) is the affective dimension of intercultural communication competence (ICC) $[1,2]$. Affective dimension refers to one's emotion that may motivate $\mathrm{him} /$ her to engage in cross-cultural interactions. Chen and Starosta argued that without the "feel" which motivates people to engage in intercultural interactions, then the actual act (behavior) of engaging in interactions would not occur. In developing and validating Intercultural Sensitivity Scale (ISS), Chen and Starosta [16] carried out three studies; the first one was to examine the dimensionality of the items using Exploratory Factor Analysis (EFA); the second one was undertaken to evaluate the concurrent validity of the instrument; and the third one was to evaluate the predictive validity of ISS. The sample used was 414 college students in the US. The EFA generated a 24-item ISS with 5 factors. The factors are interaction engagement, respect for cultural differences, interaction confidence, interaction enjoyment and interaction attentiveness. The Cronbach's alpha coefficients for the first two studies were .86 and .88 respectively.

A study by Fritz, Mollenberg and Chen [18] tested ISS in a German sample using confirmatory factor analysis. The five-factor structure was reproduced thus indicating that 
the instrument was a valid, culture free scale for measuring intercultural sensitivity. Nevertheless, the authors indicated some minor weaknesses in the operationalisation of IS.

However, a subsequent study using German and US-American data by Fritz et al. [19] failed to reproduce the five-factor structure. The data did not fit both the original and alternative model. This finding raised the question on the applicability of ISS within different contexts.

A CFA of ISS within Malaysian collectivistic setting by Tamam [14] failed to reproduce the five-factor structure; the model fit the data poorly. Hence EFA was applied to determine the dimensionality of the scale. The result of EFA was a three-factor model with 21 items. The three factors are interaction attentiveness and respect (Factor 1), interaction openness (Factor 2) and interaction confidence (Factor 3). Some of the items on the original factor loaded on other factor thus the factors were re-named accordingly. The Cronbach's alpha coefficients for the scale was .914 and the Cronbach's alpha value for the subscales were $.858, .895$ and .849 respectively.

Tamam's [14] three-factor model indicated that ISS is not culture-free. Nonetheless, with high reliability coefficients and construct validity, the three-factor model is a promising alternative IS model for Malaysian context. Tamam [14] however recommended for validation of the model through replication studies.

\section{Sampling and Data Collection Procedure}

The population of the study was undergraduate students at three higher education institutions (HEIs) in Klang Valley. Due to the heterogeneity of the population, stratified sampling was used. Based on the stratification, the sample size required was 984 . A total of 1150 questionnaires were distributed and the response rate was $92 \%$. The management of each HEI was contacted for a sampling frame. Based on the sampling frame, respondents were systematically selected. A total of 1000 questionnaires were usable after elimination of questionnaires with missing data on key constructs as well as non-response. Respondents were approached to obtain their consent to participate in the survey. They were given token upon completion of questionnaires.

A majority of the respondents $(70.8 \%)$ were Malays and the rest comprised of other ethnicities in Malaysia which were Chinese, Indians, Bumiputera and others. Slightly more than half $(54.6 \%)$ of the respondents were female while the male respondents made $42.5 \%$ of the total sample. Twenty-nine respondents, equivalent to $2.9 \%$, did not indicate their gender. A majority $(56.9 \%)$ of the respondents were in the age group of 19 to 21 ( $\mathrm{M}=$ $21.37, \mathrm{SD}=1.62$ ) suggesting that most of them were in their first and second year of study.

\section{Measurement}

The aim of this study was to further validate Tamam's [14] ISS three-factor model; therefore, the model was used. This alternative model consists of 21 items from three factors which were Interaction Openness (8 items), Interaction Attentiveness and Respect ( 7 items) and Interaction Confidence ( 5 items). The items were measured using Likert's five-point scale ranging from 1 (strongly disagree) to 5 (strongly agree). Sample items include "I respect the ways people from different cultures behave" and "I can be as sociable as I want to be when interacting with people from different cultures." 


\section{Analysis Strategy}

To validate the three-factor model obtained from EFA, as proposed by Hair et al. [20], the three-factor model was subject to Confirmatory Factor Analysis (CFA) using Analysis of Moments Structures (Amos) software.

\section{Results}

Table 1 shows the items from Tamam's [14] EFA results of the ISS three-factor model. Items with factor loading of 0.40 were included. The alpha coefficients of the subscales were good. The items were subject to CFA.

Table 1. Principal components analysis of Tamam's [14] three-factor solution of IS

\begin{tabular}{|c|c|c|c|c|}
\hline & & \multicolumn{3}{|c|}{ Factor Loading } \\
\hline Items & $\begin{array}{l}\text { Alpha } \\
\text { value }\end{array}$ & $\begin{array}{c}\text { Factor } \\
1\end{array}$ & $\begin{array}{c}\text { Factor } \\
2\end{array}$ & $\begin{array}{c}\text { Factor } \\
3\end{array}$ \\
\hline Interaction attentiveness and respect & .858 & & & \\
\hline $\begin{array}{l}\text { I respect the ways people from different cultures } \\
\text { behave. }\end{array}$ & & .896 & & \\
\hline I am open-minded to people from different cultures. & & .729 & & \\
\hline $\begin{array}{l}\text { I am very observant when interacting with people from } \\
\text { different cultures. }\end{array}$ & & .688 & & \\
\hline I respect the values of people from different cultures. & & .586 & & \\
\hline $\begin{array}{l}\text { I often show my culturally-different peers my } \\
\text { understanding through verbal or nonverbal cues. }\end{array}$ & & .554 & & \\
\hline $\begin{array}{l}\text { I try to obtain as much information as I can when } \\
\text { interacting with people from different cultures. }\end{array}$ & & .541 & & \\
\hline $\begin{array}{l}\text { I often give positive responses to my culturally } \\
\text { different counterpart during our interaction. }\end{array}$ & & .456 & & \\
\hline Interaction openness & .895 & & & \\
\hline I don't like to be with people from different cultures. & & & .804 & \\
\hline $\begin{array}{l}\text { I often get discouraged when I am with people from } \\
\text { different cultures. }\end{array}$ & & & .752 & \\
\hline $\begin{array}{l}\text { I would not accept the opinions of people from } \\
\text { different cultures. }\end{array}$ & & & .750 & \\
\hline I think people from other cultures are narrow-minded. & & & .741 & \\
\hline $\begin{array}{l}\text { I find it very hard to talk in front of people from } \\
\text { different cultures. }\end{array}$ & & & .696 & \\
\hline $\begin{array}{l}\text { I often feel useless when interacting with people from } \\
\text { different cultures. }\end{array}$ & & & .687 & \\
\hline $\begin{array}{l}\text { I get upset easily when interacting with people from } \\
\text { different cultures. }\end{array}$ & & & .682 & \\
\hline $\begin{array}{l}\text { I avoid those situations where I will have to deal with } \\
\text { culturally-different persons. }\end{array}$ & & & .663 & \\
\hline Interaction confidence & .849 & & & \\
\hline I enjoy interacting with people from different cultures. & & & & .678 \\
\hline $\begin{array}{l}\text { I am pretty sure of myself in interacting with people } \\
\text { from different cultures. }\end{array}$ & & & & .701 \\
\hline $\begin{array}{l}\text { I always know what to say when interacting with } \\
\text { people from different cultures. }\end{array}$ & & & & .681 \\
\hline $\begin{array}{l}\text { I can be as sociable as I want to be when interacting } \\
\text { with people from different cultures. }\end{array}$ & & & & .855 \\
\hline
\end{tabular}




\begin{tabular}{|c|c|}
\hline $\begin{array}{l}\text { I feel confident when interacting with people from } \\
\text { different cultures. }\end{array}$ & .651 \\
\hline $\begin{array}{l}\text { I have a feeling of enjoyment toward differences } \\
\text { between my culturally distinct counterpart and me. }\end{array}$ & .463 \\
\hline
\end{tabular}

Table 2 shows the fit indices of the three-factor model, for both the initial and fit model. In achieving model fit, three items were dropped resulting in 18-item three factor model. The model had a good fit with the latent constructs $\left(\chi^{2} / \mathrm{df}=4.885, \mathrm{p}=0.000, \mathrm{RMSEA}=0.062\right.$, GFI $=0.976$, AGFI $=0.911, \mathrm{CFI}=0.916$, TLI $=0.901, \mathrm{NFI}=0.897) . \quad$ The Cronbach's alpha value of ISS was 0.856 and the Average Variance Extracted value was 0.655 . The alpha coefficients of the subscales was $0.859,0.782$ and 0.769 respectively.

Table 2. Goodness-of-fit indices and factor loading for intercultural sensitivity

\begin{tabular}{|c|c|c|c|c|c|}
\hline Fit Indices & $\begin{array}{c}\text { Initial } \\
\text { Model } \\
(\mathrm{n}=\mathbf{1 0 0 0})\end{array}$ & $\begin{array}{c}\text { After Attribute } \\
\text { Dropped } \\
(\mathbf{n}=\mathbf{1 0 0 0})\end{array}$ & Reliability & AVE & $\begin{array}{l}\text { Recommended } \\
\text { Value }\end{array}$ \\
\hline Chi-Square & 816.6 & 635.09 & & & - \\
\hline $\begin{array}{l}\text { Degrees of } \\
\text { freedom }\end{array}$ & 149 & 130 & & & - \\
\hline$\chi^{2} / \mathrm{df}$ & 5.48 & 4.885 & & & $\begin{array}{c}\text { Equal or below } \\
5.00\end{array}$ \\
\hline RMSEA & 0.067 & 0.062 & & & $\begin{array}{c}\text { Equal or below } \\
0.08\end{array}$ \\
\hline GFI & 0.921 & 0.932 & & & $\begin{array}{c}\text { Equal or above } \\
0.90\end{array}$ \\
\hline CFI & 0.892 & 0.916 & & & $\begin{array}{c}\text { Equal or above } \\
0.90\end{array}$ \\
\hline Factor 1 & & $\begin{array}{c}0.604,0.562, \\
0.693,0.756,0.7 \\
0.724,0.648, \\
0.549\end{array}$ & 0.859 & 0.65 & $\begin{array}{c}\text { Equal or above } \\
0.30\end{array}$ \\
\hline Factor 2 & & $\begin{array}{c}0.586,0.68 \\
0.655,0.689 \\
0.638\end{array}$ & 0.782 & 0.65 & $\begin{array}{c}\text { Equal or above } \\
0.30\end{array}$ \\
\hline Factor 3 & & $\begin{array}{c}0.648,0.684 \\
0.524,0.613 \\
0.639\end{array}$ & 0.769 & 0.62 & $\begin{array}{c}\text { Equal or above } \\
0.30\end{array}$ \\
\hline
\end{tabular}

\section{Discussions and Conclusion}

The aim of this study was to further validate Tamam's [14] ISS three-factor model within Malaysian cultural context. Validation was done by subjecting the three-factor model produced using EFA to confirmatory factor analysis. Based on the indices, Tamam's [14] ISS three-factor model demonstrated unidimensionality, construct validity and good internal consistency. This validation lent support to Tamam [14] and Fritz et al.'s [19] findings which indicate that ISS is not culture-free. Therefore, it must be used with precaution within different cultural context. The present study contributed to the body of 
knowledge by validating an instrument to measure intercultural sensitivity within Malaysian context. ISS three-factor model shows potential and can be used as an instrument in relevant cultural-related research and training.

\section{Acknowledgements}

Findings in this study are part of the doctoral work by Norzita Yunus, a PhD candidate at Universiti Putra Malaysia.

\section{References}

1. G. M. Chen, ICS. 19, (2010)

2. G. M. Chen, W. Starosta, HC. 1,(1997)

3. J. Chocce, IJIRIS. 1, 5-11 (2014)

4. D. R. E. Cotton, R. George, M. Joyner, IETI. 50, (2013)

5. D. K. Deardoff, JSIE. 10, (2006)

6. M. R. Hammer, M. J. Bennett, R. Wiseman, Int J Intercult Relat. 27, (2003)

7. J. -E. Jon, JSIE. 17, 455-470 (2013)

8. M. W. Lustig, J. Koester, Intercultural competence: Interpersonal communication across cultures. 6th ed. (2010)

9. G. S. Matkin, J. E. Barbuto, JLOS. 19, (2012)

10. C. L. Olson, K. R. Kroeger, JSIE. 5, (2001)

11. L. T. Tran, L. Pham, CCOM. 20, (2015)

12. S. Llyod, C. Hartel, JMP. 25 (2010)

13. P. G. Altbach, L. Reisberg, L. E. Rumbley, UNESCO Report for world conference on higher education (2009)

14. E. Tamam, JICR. 39, 173-183 (2010)

15. A. A. Kamal, G. Maruyama, IJIR. 14, (1990)

16. G. M. Chen, W. Starosta, HC. 3, (2000)

17. D. Matsumoto, H. C. Hwang, JCCP. 44, (2013)

18. W. Fritz, A. Mollenberg, G. M. Chen, ICS. 11, (2002)

19. W. Fritz, A. Graf, J. Hentze, A. Mollenberg, G. M. Chen, ICS. 14, (2005)

20. J. F. Hair, W. C. Black, B. J. Babin, R. E. Anderson, Multivariate data analysis : A global perspective. 7 th ed. (2010) 